\title{
Cultivating Problem-Solving Scholar- Practitioners: Impact of One CPED Program on Leader Self-Efficacy
}

\author{
Nancy Akhavan and Nichole Walsh* \\ California State University, Fresno, California, USA \\ https://orcid.org/0000-0001-7679-9793 \\ https:/ / orcid.org/0000-0003-1426-0551 \\ Janeen Goree \\ Fresno Pacific University, Fresno, California, USA \\ https://orcid.org/0000-0001-8407-352X
}

\begin{abstract}
This single case study is a qualitative inquiry into the cultivation of doctoral candidates and graduates on their efficacy as leaders in using inquiry as to approach problems of practice in daily work. The study examined a doctoral program in educational leadership at one large public university in California, USA. The case study methods included artifact analysis, an examination of field notes, and semi-structured oneon-one phone interviews. The data analysis of all sources revealed three themes related to participants' leader self-efficacy in using scholarly inquiry on problems of practice in the field. Findings indicate that the participants grew in their leader self-efficacy, transformed, and confident in their sense of self as an educational scholar-practitioner to enact change. As a result of their experience in a Carnegie Project on the Education Doctorate (CPED) program, graduate participants also highlight the focus on inquiry processes to solve problems of practice as vital to educational leadership. Conclusions highlight considerations for similar programs when evaluating how they prepare graduates to impact education beyond coursework. Further research should emphasize how programs are addressing problems of practice for social justice to impact educational leaders in the field upon program completion.
\end{abstract}

Keywords: education doctorate; leader self-efficacy; scholar-practitioner; problems of practice; educational leadership

\section{Introduction}

In the past, researchers critiqued the education doctorate (EdD) by examining characteristics of various programs and candidates uncovering challenges in

\footnotetext{
*Corresponding author: Nichole Walsh; Email: nwalsh@mail.fresnostate.edu
} 
developing leaders for local impact on issues within the communities they serve (e.g., Levine, 2005; Murphy \& Vriesenga, 2005). Later, researchers found that there is hope within the scope of graduating doctoral candidates, when programs aim to develop new leaders as scholar-practitioners who challenge the status quo (e.g., Zambo, 2013; Zambo, Buss \& Zambo, 2015). Through the reframing of the EdD in this way, programs can focus on a rigorous curriculum that cultivates graduates who can take with them the critical skills of scholarly inquiry, coupled with problem-solving of systemic issues in the communities they serve (Buss, 2018).

A body of research has focused on the reconfiguration of the EdDin this way (Hovannesian, 2013; Peterson, 2017; Welch, 2013); however, more consideration is needed on how candidates transfer learning problems of practice in an academic setting to the real-world work environments as future educational leaders (Zambo et al., 2015; Vasudeva, 2017). As Zambo et al. (2015) indicate, understanding the candidate-to-leader identity is one of the most relevant topics to consider for redesigning doctoral programs for graduates. Not only because of the broader societal issues, but also because of the management challenges new school leaders encounter daily in the field (Arrieta \& Ancho, 2020).

This paper explores how one redesigned model, the Carnegie Project on the Education Doctorate (CPED), positively impacts program graduates and the organizations for which they serve. Inquiry as Practice is a guiding principle of CPED programs where candidates are guided in:

"The process of posing significant questions that focus on complex problems of practice and the ability to gather, organize, judge, aggregate, and analyze situations, literature, and data with a critical lens." (CPED, 2019b, Design-Concepts Upon Which to Build Programs, para. 5).

A second guiding principle relevant to this study is Scholarly Practitioner where candidates are supported in:

Blend[ing] practical wisdom with professional skills and knowledge to name, frame, and solve problems of practice. They use practical research and applied theories as tools for change because they understand the importance of equity and social justice. (CPED, 2019b, Design-Concepts Upon Which to Build Programs, para. 3).

When working to transform EdD programs, it is pertinent to understand how intentionally threaded experiences of scholarly inquiry alongside classroom learning can impact graduates' educational leader self-efficacy (Hannah, Avolio, Luthans \& Harms, 2008; Hannah, Woolfolk \& Lord, 2009) in "the new and emerging developmental conditions that prevail in early twenty-first century cities and regions" (Gibney, 2011, p. 614).

\subsection{Research Questions}

Using a single post ex facto case study framed by the CIPP evaluation model for quality education (Aziz, Mahmood, \& Rehman, 2018), researchers explore to understand the following questions:

- How does a CPED doctoral program support candidates in cultivating their leader self-efficacy as problem-solving scholar-practitioners?

- To what extent do CPED program graduates, as scholar-practitioners, continue to solve problems of practice in the field? 


\section{Guiding Frameworks}

Two frameworks guided the research evaluation design and qualitative analyses for this case study: The CIPP model for quality evaluation in educational settings and Leader Self-Efficacy.

\subsection{Conceptual Framework: The CIPP Model for Quality Evaluation}

The CIPP (Context, Input, Process, Product) evaluation model was designed to help organizational leaders make data-based decisions for program improvement. Further, the CIPP model also considers how findings can be communicated and applied across various stakeholder levels (Stufflebeam \& Zhang, 2017). Context evaluation is based on various data collection methods such as reviewing supporting literature, program documents, archived artifacts, and stakeholder interviews and surveys. The aim is to understand the program's general nature, purpose, and goals (Stufflebeam \& Zhang, 2017). Input narrows the evaluation to specific or unique aspects of the program being studied, and Process evaluation considers how well those aspects are meeting intended goals and objectives for the learners. These evaluation components require data from stakeholders with intimate knowledge of the program and implementation of aspects under evaluation (Fitzpatrick et al., 2004). Product, the last evaluation component, uses findings and analyses across multiple data sources to conclude program effectiveness to inform decision-makers on the most appropriate next steps to improve teaching and learning (Sancer, Baturay \& Fadde, 2013; Aziz et al., 2018).

This model's strengths, specifically in the context of the post ex facto design (Creswell \& Poth, 2018), allow for a nonlinear and non-time bound approach (Stufflebeam \& Zhang, 2017). Instead, the analyses are based on the findings from multiple sources of data to provide a rich understanding of the program, intended outcomes, and impact on the adult learners to draw conclusions and make recommendations for improvement and sustainability (Fitzpatrick et al., 2004; Stufflebeam \& Zhang, 2017; Wang, 2010). Furthermore, this evaluation framework can provide considerations for practitioners with similar programs and inform future research (Aziz et al., 2018). Additionally, unlike others, the CIPP evaluation model is aimed at understanding the role teaching and learning play in the program context (Stufflebeam \& Zhang, 2017), making it a strong fit for a case study in education.

Aziz et al. (2018) implemented the CIPP evaluation model for a school-level case study, validating through triangulation of mixed-methods, a conceptual framework specific to education. Figure 1 outlines the model used to frame the post ex facto case study analyses in this evaluation. 


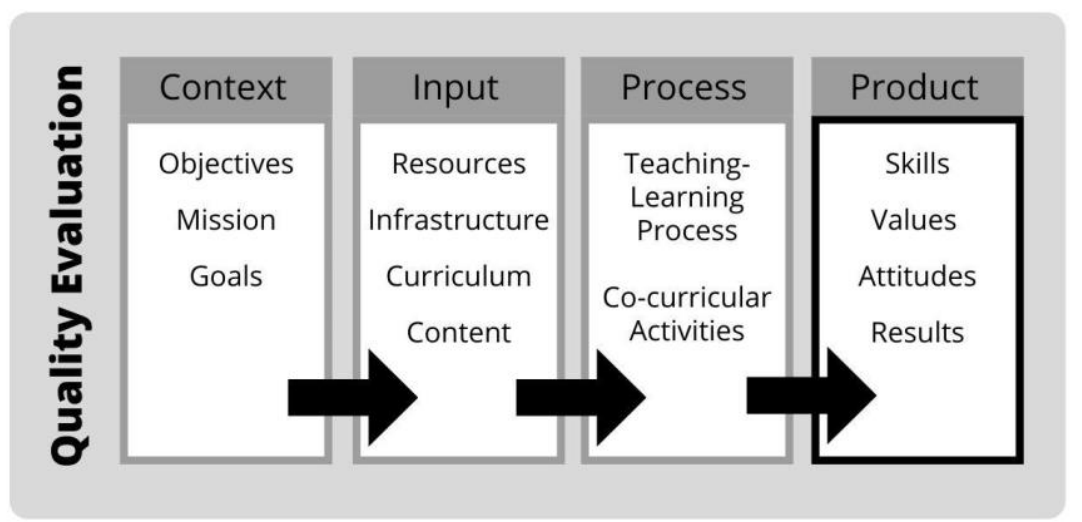

Figure 1: CIPP Model for Quality Evaluation (Aziz et al., 2018, p. 195)

\subsection{Theoretical Framework: Leader Self-Efficacy}

Leader Self-Efficacy (LSE; Hannah et al., 2008; 2009; 2012; 2013), the theoretical framework for this study, stems from Bandura's theory of self-efficacy which explains behavioral changes. Bandura's (1977a) construct of self-efficacy defined perceived self-efficacy as the belief in one's capabilities to organize and execute a course of action required to produce an outcome. Bandura (1977b) describes that psychological features, like thoughts and reactions, will affect a person's selfefficacy belief's. Bandura's theory suggests that a person's belief in their ability to have mastery over an outcome will increase their willingness even to try and persist (Bandura, 1977a). When specifically looking at self-efficacy in a leaders context, the more a leader accesses a wide-array of self-efficacy constructs, the more they will perceive their ability to resiliently handle various challenges that inevitably lie ahead (Hannah et al., 2009; 2012). These foundational theories correspond to the construct mentioned above as a problem of practice where a strong belief in one's ability to apply critical inquiry to solve challenging issues is vital.

Hannah, Avolio, Walumbwa and Chan (2012; 2013) established and validated a multifaceted Leader Efficacy theory and measurement with two factors: leader self- and means-efficacy. The complex constructs from Hannah et al. (2012; 2013) can be generalized as follows: Leader Self-Efficacy regards the internal shifts on what the leader believes they can do, while Leader Means-Efficacy regards the external actions and transactions within the context of the organization and others being led. For this case study to evaluate program impact on candidate learning, the theoretical framework was delimited the single factor of Leader Self-Efficacy (LSE) because it is within direct program influence.

Hannah et al. (2008; 2009) first formalized LSE as a layered construct built on the interactions of leader-efficacy in:

1. thought, the perception of ability to find solutions to complex issues;

2. self-motivation, the perception of the amount of effort to be given towards a challenging situation;

3. means, the perception of access to resources and how this may affect the leader's ability to address a challenge; and 
4. action, the leader's performance based on the subsequent construct in a given leadership contex, $t$ which becomes increasingly more automatic over time and experience. These constructs provided the lens through which this case study could examine the perspectives of CPED program graduates to explore and evaluate how the program develops LSE to assist new leaders in solving problems of practice in a diverse local setting after graduation.

\section{Methods and Procedure}

A single post ex facto case study method (Cresswell \& Poth, 2018) framed by the CIPP Model for Quality Evaluation (Aziz et al., 2018) was most suitable to conduct an inquiry into graduate's perspectives from one CPED program at a large public university in California. The case study approach integrates information sources and allows analysis from different viewpoints (Cresswell \& Poth, 2018) after program completion. The evaluation model for the case study method used stakeholder perspectives and experiences through interviews and reflexive journaling alongside documents, archived data, and associated program literature to understand the unique program aspects within the broader CPED context and conclude their impact on graduates' LSE. This model is supported by Denzin's (2017) focus on qualitative inquiry methods to shape information that is not collected in a number-focused study, which the CIPP model does not require for evaluation (Aziz et al., 2018). Although this method's findings are difficult to generalize, the understanding of one case can develop a perspective of what is happening in the field, which can shape practitioner considerations for similar contexts and inform further research (Cresswell \& Poth, 2018).

\subsection{Participant Sample}

The study design for the CIPP evaluation used a representative random sample (Cresswell \& Poth, 2018) of 12 volunteer participant graduates from one CPED inspired program. The doctoral leadership program adopted a cohort model, with half focused on PreK-12 and the other half on higher education. This study was conducted, with human subject research approval, using the program's archived database. The database included student names, contact information, job position while the student was in the program, their current job status as provided, and the year they graduated. There were approximately 150 graduates across program cohorts; thus, a goal of $10 \%$ for the participant sample was set, and 15 graduates would be contacted.

All names were entered into an Excel sheet to choose the 15 graduates as a representative sample (Cresswell \& Poth, 2018). After the sheet was printed, the names with identifying information were cut into strips and placed into an envelope where 15 strips were randomly selected and five additional were drawn as alternates. The principal investigator contacted possible participants via phone and moved to the next name on the list after three attempts, which garnished 12 total interviews. The participants' demographics reflected that of the overall program graduate population with the following breakdown reported: Gender (7female, 58.3\%; 5-male, 41.7\%; 0 other); Race/Ethnicity (5-Hispanic, 41.7\%; 1African American, 8.3\%; 2-Asian American, 16.7\%; 4-white, 33.3\%); Program 
Focus (5-higher ed, 41.7\%; 7-p-12, 58.3\%); Currently in Formal Leadership Role (12-yes, 100\%; 0-no).

\subsection{Data Collection}

The approved case study used three post ex facto data sources for the evaluation model: (1) interviews with volunteer graduates, (2) volunteer graduates' dissertations as samples of problems of practice inquiry, and (3) observational notes of teaching and learning from one aligned DPELFS leadership course. Additionally, one researcher kept a reflexive journal during the interview process and had access to archived program syllabi, student work samples from one program course, and participants' dissertations. Member-checking was used throughout the analyses to enhance credibility (Cresswell \& Poth, 2018). For increased dependability, case study protocols were defined and followed with adherence to transcription standards using a professional, confidential service (Chowdhury, 2015).

\subsubsection{Semi-Structured Interviews}

Semi-structured interviews were chosen because of the flexibility the researcher has in asking questions beyond the protocol to delve deeper into issues and points the interviewee discusses (Cresswell \& Poth, 2018) necessary for the CIPP model (Aziz et al., 2018). All interviews were conducted over the phone for the participants convenience and confidentiality due to the study's evaluative nature. Any identifiers were removed at transcription, and individual participant letters were assigned to their responses to enhance confidentiality further.

The interview protocol included 12 questions organized into three sets. The first two questions oriented the participant and the interviewer for rapport (Denzin, 2017; Cresswell \& Poth, 2018). The next three questions concentrated on using problems of practice while in the program. While the following three questions considered their current leadership role and how they integrate problems of practice to enact change. The next four were evaluative to capture the CIPP elements in developing LSE. The final question invited participants to provide additional information concerning how the program supported their growth. The interview protocol is located in appendix 1 .

\subsubsection{Program Literature, Artifact, and Document Review}

The use of literature, artifacts, and documents is essential to triangulating qualitative case study findings (Denzin, 2017; Creswell \& Poth, 2018). For the CIPP Model for Quality Evaluation, these collected data should be specific to understanding the case study program and participant outcomes (Aziz et al., 2018).

For this evaluation case study, as program graduates, participants had completed their dissertations in practice and took a leadership course on implementing and sustaining change in organizations. The course included field-based practicum, where candidates investigated a problem of practice in authentic field-based settings in PreK-12 organizations or institutions of higher education. The researcher taught this class and had study approved access to archived syllabi, four years of student work and teaching notes, and the final examination papers written by study participants and other candidates. These papers specifically 
outlined solutions to the complex problems identified based on action research in the field throughout the semester. Dissertations were publicly available on ProQuest with full access to university faculty. Other program documents and literature were also publicly available via the case study program's university website, the CPED website, and through EdD and CPED aligned peer-reviewed journal articles.

\subsubsection{Reflexive Journal}

One researcher, with instructional experience in the program, kept a reflexive journal (Rettke, Pretto, Spichiger, Frei \& Spirig, 2018) to record notes throughout the data collection process. The aims were three-fold. First, to continue mitigating potential biases using reflective self-monitoring during evaluation. Second, to capture metacognitive connections made by the researcher between the findings and the researcher's professional experiences, only a principal investigator close to the program's work could deeply understand. Third, to increase rigor by allowing a second and third researcher to later review for mitigation of bias within the post ex facto CIPP evaluation (Rettke et al, 2018).

\subsection{Data Analysis}

Once the interview transcripts were checked through member checking by the participants (Creswell \& Poth, 2018) and the interview transcripts were stored for a later review. The researchers used a collaborative hybrid qualitative thematic analysis (Denzin, 2017) to support the CIPP model evaluation components. Framed by the theory of Leader Self-Efficacy (Hannah et al., 2008; Hannah et al., 2009), themes from response convergence on perceptions of program impact emerged (Denzin, 2017) and were used within the evaluation model alongside the other data.

After the interviews, the principal investigator launched upon organizing and examining documents and files that she had from her work as an instructor of a core course in the program. She embarked upon this examination of documents to fully understand the participant, their background, their learning processes, and their current leadership position responsibilities to prepare for the CIPP evaluation with the supporting researchers (Chowdhury, 2015).

The principal investigator continued to keep notes in the reflexive journal to note her feelings when reading the transcriptions and match the transcriptions to assessment notes, papers written by each individual, and field notes when teaching each participant in the class. Thoughts and feelings were noted for later review to mitigate potential coding biases (Creswell \& Poth, 2018). These notes were referenced during the CIPP evaluation for supporting researchers to member check potential areas of bias and as a piece of stakeholder data within the Input and Process evaluations (Anzin, et al, 2018).

\subsection{Limitations}

The primary limitation is researcher bias as the principal investigator (PI) of this study is highly involved in all aspects of the case study CPED program and the candidates' experiences. At the time of the study, the PI had taught one core course for five years working with seven face to face and five online cohorts. Candidates examined an authentic PreK-12 or higher education field-based 
problem of practice in this course. Furthermore, the PI has chaired numerous dissertations, guiding candidates through inquiry into the problem of practice they have identified for their research agenda. This bias was essential in developing rapport with the graduate candidates as they had great comfort in sharing personal narratives in the field with the researcher. The researcher also understood the program nuances and concepts presented in the interview narratives that one from the outside would require further exploration before analysis. On the other hand, intentional mitigation of bias that could affect validity was addressed by including two research colleagues. At the time, one was not involved as faculty in the CPED, and the other was a non-CPED instructor at a different university. These additional researchers worked to member check each step of the findings and analytic processes ensuring higher objectivity (Chowdhury, 2015; Denzin, 2017).

\section{Findings and Discussion}

Using the CIPP model for quality evaluation framework, this single post ex facto case study aimed to explore the following:

- How does a CPED doctoral program support candidates in cultivating their leader self-efficacy as problem-solving scholar-practitioners?

- To what extent do these CPED program graduates, as scholarpractitioners, continue to solve problems of practice in the field?

Findings and emergent themes are presented in conjunction with the analyses appropriate to each component of the CIPP evaluation and the literature review: Context, Input, Process, Product.

\subsection{Context Evaluation}

Pertinent to the Context evaluation is to understand the educational goals and objectives of the program and the larger mission for social impact (Aziz et al., 2018). Through document and aligned literature review, findings highlighted that graduates from CPED aligned programs, as is the one under evaluation, are provided progressive leadership goals for practice and application in the field at the PreK-12 and higher education levels.

The program under review is part of the Carnegie Project on the Education Doctorate (CPED), a consortium of over 100 colleges and schools of education in the United States and Canada focused on reconfiguring EdD programs through a critical focus on rigor and change in curriculum development (CPED, 2019a). The CPED framework (CPED, 2019b) guides the redesign of programs around progressive questions of equity, ethics, and social justice to bring about solutions to complex problems of practice and prepare leaders who can make a positive difference in the communities they serve. Students in CPED programs are expected to develop collaboration and communication skills for working with diverse communities with embedded field-based opportunities to apply to learn to find solutions for real-world problems. With these frames, CPED programs should link theory and systematic inquiry to emphasize the generation and transformation of professional knowledge and practice to enact social justice change in local settings (CPED, 2019a). 
Three CPED framework (2019b) guiding principles - one, four, and five - were highlighted across the documents and artifacts collected for this program evaluation as insight into these progressive notions of school leadership. Principle one frames the purpose of the education doctorate to address questions on equity, ethics, and social justice for solutions to complex problems of practice. Principle four indicates that programs use field-based opportunities with candidates to analyze problems of practice and use multiple frames to develop meaningful solutions. Principle five states the program should be grounded in and develops a professional leadership base that integrates practical and research knowledge, linking theory with critical inquiry. Students within CPED programs are expected to also learn through inquiry (CPED, 2019a). The program under evaluation for this case study, as designated a CPED affiliate, is to intentionally thread inquirybased learning through to the capstone experience (CPED, 2019b).

As such, CPED candidates should begin to integrate the take-aways from case study analyses in the classroom into authentic action research in the field, increasing the likelihood that effective leadership practices will become part of their repertoire, thereby increasing collective organization success (e.g., Hamann \& Trainin, 2018; Peurach, 2016; CPED, 2019a). The larger goal is that graduates apply these experiential leadership lessons in inquiry to their job contexts, no matter where they are positioned within an organization. When a steady focus on improving educational contexts is implemented, there is a greater impetus for improving student learning outcomes, an emphasis on scalable actions, and also a movement away from the diffusion of innovations toward sustained, coordinated efforts that result in widespread change (Peurach, 2016) that the redesigned CPED program, like the one under evaluation, is aiming to achieve (CPED, 2019a). Additionally, CPED programs utilizing a cohort model to cultivate scholar-practitioners to solve complex problems of practice have made the most impact on developing efficacious and effective change leaders in local contexts (e.g., Hamann \& Trainin, 2018; Kennedy, Bondy, Dana, Vescio \& Ma, 2020; Cunningham, VanGronigen, Tucker \& Young, 2019). Evidence of these CPED affiliate expectations and research-based best-practice - developing cohorts of educational leaders in PreK-12 and Higher Education as problem-solving scholarpractitioners for social justice and organizational change - were found within the program website and handbook, course syllabi as signature assignments and field experiences as well as the principal investigator's reflexive journals and teaching notes.

To appreciate this CPED program's goal - developing educational leaders for social justice and change - understanding the region for which graduates practice as educational leaders were essential to explore within the Context evaluation. The university is situated in an area of California that is considered to be high in poverty and low in educational attainment, ranked $15^{\text {th }}$ in the nation for people living in poverty $(28.1 \%)$, and nearly 80 percent of those living in the Fresno area have not earned a bachelor's degree (Ramsey, 2019). Along with high poverty rates, the region has large numbers of immigrants and non-citizens with a variety of cultures and languages (Sierra Health Foundation, 2016). The diverse backdrop is the community in which the doctoral graduates from this CPED program serve. Reviews of student assignments, instructor discussion notes, dissertation topics, 
and interview responses highlighted the challenges presented across this geographical region with systemic societal oppression that PreK-12 and higher education institutions are working to ameliorate by educating the populace. For example, various submitted assignments over the four years noted ways candidates were grappling with challenges related to the level of poverty and education of most residents within their districts and institutions of employment. The website highlighted several candidate quotes appreciating the "real-world experience of [program] faculty" because they understood the challenges and needs of the community they will lead. For triangulation, evaluation findings showed many of the core graduate faculty, as noted on the program's website links to Curriculum Vitas during document analysis, had current connections to local PreK-16 institutions, also noted as a vital CPED program practice (Auerbach, 2011; Peterson et al., 2016). Thus, as a CPED affiliate, the Context evaluation findings illustrated how the program focused on scholarly inquiry to support finding solutions to problems of practice in the regional demographic contexts with community-engaged faculty with some reference to issues of social justice.

\subsection{Input Evaluation}

For Input evaluation, the conceptual framework outlines the focus on resources, infrastructure, curriculum, and content to address the program's needs within the established context (Aziz et al., 2018). For this case study, and based on the Context evaluation findings, the Input evaluation was delimited to curriculum and content.

In alignment with these CPED program graduates' contexts, the syllabi and signature assignment content illuminated the program's understanding that these educational leaders will face complex issues. Further congruence of document, artifact, and reflexive journal review findings highlighted this specific CPED program focused curriculum and content on scholarly inquiry to find solutions to new problems of practice in the field to support LSE in a changing landscape. Based on document review, this program recognized a problem of practice to frame leader inquiry as action research into a situation currently puzzling an organization without a static or straightforward answer (Pollack \& Ryan, 2013). Further analyses of field notes and documents also revealed this inquiry into problems of practice as a significant point of the program. Nine core courses listed some type of problem-solving through a scholarly inquiry approach as a student outcome. The terms seeing problems, problem-solving, or seeing problems of practice were used 22 times across participant responses and was the most repeated point made. Likewise, a review of assignments revealed prompts that pushed candidates to framework-based situations as problems of practice and consider how they might approach complex real-world issues to develop LSE beyond program completion expectations (Hamann \& Trainin, 2018).

It was also discovered that most program instructors identified the cycle for continuous improvement as the method for problem analysis and solution planning. One core course syllabus, for example, noted a candidate learning outcome as, "Graduates will be able to lead collaborative team building and create solutions to problems that demonstrate ethical and sound instructional leadership through the cycle of continuous improvement." Through circumlocution, 19 participant 
responses also referenced learning the continuous improvement model to approach problems in the field. Making a statement about the course content regarding the continuous improvement model, for example, one participant explained:

"[The program] gave me different lenses to look at the issues. We looked at different learning experiences, perspectives, problem-solving, and their impact. The content in the classroom shaped our practice solving problems in the field."

Another participant explained more on learning the concept of systems analysis for organizations, such as the cycle of improvement, was a focus in one core course, and this understanding appeared to be one that participants understood and carried with them into field-based practice. For example:

"The program offered...the practitioners' a framework, so to speak, across the board. We were charged with doing something in what you're doing right now, learning from other people what they have applied currently, or found successful. So, I guess the program is designed specifically to work from the problem-solving model in the field for improvement."

Gibney's (2011) description for reframing and Cunningham, VanGronigen, Tucker \& Young's (2019) focus of using powerful learning experiences in leadership development also aligns with concepts around organizational responsibility and sustainability this CPED program infused into course learning outcomes as referenced across syllabi and signature assignments. With the overarching CPED Principle One illustrated social justice topics within each core and elective syllabi and central to the change leadership course instructed by the principal investigator, the program values education's social responsibility for equity and access across contexts. Participant's responses triangulated the teaching of social justice concepts through referenced terms such as leading for equity, advocating for change, and amplifying voices. For example, one participant who identified as "a minority who feels marginalized, especially in leadership roles," eloquently described this in terms of becoming an advocate for candidates and others she serves:

"The program has given me the knowledge, as well as the wisdom and...the courage to really be the voice for the candidates and maybe even amplify voices of people we mentor when they may not have one."

Another participant who recognized his "privilege as a white male in leadership positions" explained considerations he learned in the program:

"[The courses] challenged me to consider my biases and identities coming to problems of practice as a leader. The way I come to the problem is not how others have experienced it, so understanding the cycle of improvement from an equity perspective means I must ensure all voices are at the table and part of the collaborative processes for finding solutions. Otherwise, what have we really changed?"

\subsection{Process Evaluation}

The Process evaluation focuses on understanding the program's teaching and learning strategies and co-curricular activities that support the program's goals and expected student outcomes (Aziz et al., 2018). While the review of syllabi, 
signature assignments, student assignments, teaching notes, and reflexive journaling revealed many approaches to teaching and learning across instructional experiences, there was convergence across data regarding the use of case studies and literature reviews for scholarly inquiry into real-world problems of practice from the frame of the respective course content all with the intent of shaping student leadership skills as a general construct. Many courses also incorporated field-based experiences as an applied application of learning to practice new leadership skills in context. These types of contextual experiences, within the LSE framework, can shape perceptions of ability and access to resources for solving complex issues, which impact the effort given and automaticity to act in challenging situations (e.g., Hannah et al., 2013).

Focusing on a problem of practice requires decision-making processes to examine a real-time case to effectively move forward with a leadership action across organizational contexts for various purposes, even outside of teaching and learning (Chitpin, 2014). Hamann and Trainin (2018) note that establishing a system of inquiry into a problem of practice is essential to developing scholarpractitioners; also, factors found to impact LSE (Hannah et al., 2008; Hannah et al., 2009). Without the skills needed to first engage in deep inquiry for continuous improvement, leaders will fall back on status quo approaches to making decisions rather than draw on the visionary and collaborative processes needed for real change in schools (Morrison, 2018). Field notes revealed that the principal investigator, as the change leader instructor, regularly incorporated peerreviewed case studies to teach inquiry into problems of practice using the cycle of continuous improvement model with small groups of candidates.

Furthermore, critical discourse and inquiry, becoming increasingly popular ways to frame teaching and learning in higher education (Rogers et al., 2016) with a focus on collaborative discussion and problem-solving across leadership preparation instruction (Jenkins, 2020), were also emphasized strategies for the CPED instructors as noted across seven syllabi course overviews. Students from this CPED program are also expected to become skilled in a type of critical discourse - the two-way change process of leadership (Fairholm, 2014) - within the principal investigator's change leadership course. The two-way change process of leadership (Fairholm, 2014) requires candidates to take the individual and personal notions of leadership and adapt them to organizations' issues within which they work, essential to field-based assignments. Participant interview responses illustrated that, as PreK-12 and higher education leaders who work in professional educational communities, they were involved in the two-way leadership change process by examining problems of practice regularly throughout the program. Triangulation of data found convergence on the use of real-world case studies to teach scholarly inquiry into problems of practice to discover how leaders who have gone before them have approached difficult problems. Furthermore, the intent was to use the new understandings to shape leadership skills vicariously, somewhat like an apprenticeship model, as noted in the reflexive journal and the student assignment responses, to impact overall LSE (Hannah et al., 2013) in the field-based experiences. 
The program also highlights the use of Gibbs' (1988) model of reflection in many of the core course syllabi to assist candidates in this two way leadership exchange. Much like Thanaraj (2016) delineates with her autoethnography on using reflection to impact leadership skills, Gibb's (1988) reflective structure has candidates consider learning experiences, including the interactions with stakeholders, to understand what they would do differently for more robust outcomes. The model also adds an introspection, drawing on emotional intelligence through awareness of feelings and internal thought patterns (University of Cumbria, 2020).

Furthermore, while the term inquiry was not always explicitly used, case studies informed what and how strategies were applied in the improvement cycle noted across 10-course syllabi. Course outcomes also aimed to cultivate leadership skills to think and deal with field-based complexities through engagement in dynamic, collaborative organizational processes with high levels of emotional intelligence and cultural awareness (Cunningham et al., 2019; Sudirman \& Gemilang, 2020). These skills can be taught effectively through powerful learning experiences using collective inquiry at the intersection of theory, research, and practice for the critical examination of authentic problems of practice (Cunningham et al., 2019) and in work-based settings (Sudirman \& Gemilang, 2020). These skills, as a component of LSE (Hannah et al., 2013), are also developed with the incorporation of field-based action research as a model of scholarly inquiry (Lenihan et al., 2015), for which the triangulation of findings revealed was central to this CPED program instructors pedagogy.

\subsection{Product Evaluation}

The Product evaluation allows for data review through the lens of actual outcomes, positive or negative, as aligned to the established program goals (Aziz et al., 2018). As a CPED aligned program working to develop educational leaders, this case evaluation presented the unique ways the CPED principles were being presented in the curriculum and taught in and out of the classroom. The evaluation up to this point illuminated that the program desires new leaders understand their social responsibility to the field of education and hone the skills to think through complex situations, engage groups in organizational change and focus on sustainability with high emotional intelligence for social change (Cunningham et al., 2019; Sudirman \& Gemilang, 2020). The program considered how leadership has to be reframed and aligned for organizational change needs (Gibney, 2011; Morrison, 2018) and transitioned to the real-world (Zambo, Ross \& Zambo, 2015; Vasudeva, 2017), which is an overarching tenet of CPED aligned programs (2019) and threaded throughout this case study evidence. The first three evaluations illustrated that this CPED program's goal is to develop change leaders for the future, explicitly drawing upon and cultivating student inquiry into problems of practice in the field during the program and continuing after graduation. Leader Self-Efficacy (Hannah et al., 2013) provided a framework for exploring how these program graduates have developed as leaders and how they face leadership situations in the field to evaluate the program's effectiveness in meeting the intended goals and learning objectives. 
The participant interview responses on applying program learning objectives and experiences were analyzed for emergent themes and evaluated for growth in LSE (Hannah et al., 2013) as the ultimate program outcome goal. Next, the themes guided the researchers' understanding of the evaluation questions (1) How does a CPED doctoral program support candidates' in cultivating their leader self-efficacy as problem-solving scholar-practitioners? (2) To what extent do CPED program graduates, as scholar-practitioners, continue to solve problems of practice in the field?

Trends from interview participant response emergent thematic analysis (Denzin, 2017) triangulated with the archived document review through the previous evaluation findings illuminated the program impacted LSE and inquiry is a learned skill developed through the program's focus on problems of practice. The most emphasized points, aligned with the framework of LSE in thought, selfmotivation, means, and action, were as follows:

1. personal transformation as a leader;

2. increased confidence as a leader to enact change; and,

3. seeing inquiry as a program learned skill to solve problems of practice as leaders in the field.

The participants discussed growth in approaching problems of practice as leaders in their work contexts because of the program. They also perceived that learning to inquire into a problem of practice based on research was a program-developed skill important in strengthening their ability to lead in the field after the program.

\subsubsection{Theme one: Personal transformation in LSE of thought, self-motivation, and action}

As outlined from the previous evaluation components, an overarching goal of this CPED program is that candidates become leaders who can lead organizations to address complex problems of practice. As foundational to Leader Self-Efficacy (Hannah et al., 2013), the leader must believe they have the thought, selfmotivation, and means to act, in this case, to find solutions for challenging situations in the field. Across responses, program graduates emphasized how their leadership ability was strengthened by cultivating personal characteristics, skills, and ideas that motivated them to act as leaders with more efficacy and confidence. This finding aligned with aspects of effective change-leader development noted throughout the previous evaluation findings (e.g., Cunningham et al., 2019; Gibney, 2011; Morrison, 2018; Sudirman \& Gemilang, 2020; Vasudeva, 2017; Zambo, Ross \& Zambo, 2015).

The term change related to personal transformation as a leader was mentioned 17 times in the interview transcripts. Participants described being transformed from their learning and interactions in this doctoral program, and that they perceived themselves differently as leaders because of the program. For example, two participants mentioned a change in self as "stepping out of the comfort zone." Another participant described their experience as follows: "I am much more understanding, more patient,... I am a much more holistic leader now... miles and miles more patient,... it was literally transformational." A further participant shared, "...on the good side, it has completely transformed me in a way that I see things differently." 
Another participant was straight forward in how they changed as a leader through the program, stating, "I've changed as a leader because I look at problems and I know that I can do something to address them. The skills that I have learned in analysis and in using data to make generalizations about an issue have been invaluable and I see myself as a problem solver." Similarly, a different participant described their transformation after sharing a moment that happened in a meeting early on in the program, when the comments of another person made them cry:

"I'm a very different person now because of [the program], regardless of what people thought of me at the beginning. I think it's made me a better employee. It makes me a servant leader. It's made me the type of person that I never was before, someone stronger, which gave me the ability to view myself as someone who had something to offer."

Six other participants elaborated on developing a voice, also indicating LSE transformation.

Similarly, another participant highlighted how the CPED program aided their leadership transformation and observed peers' transformation through finding and using voice. They described how communicating needs became the motivation to make leadership moves that might have otherwise been avoided, which is an increase in LSE, specifically in means for action:

"[The program] has given us leaders the courage to say, 'you know, if you want something, voice it.' If you want something you need to seek it. It gave us that push, you know, the push to actually do something as a leader rather than hope or wish for it."

\subsubsection{Theme two: Increased confidence as LSE in thought and means impacts self-motivation and action to lead}

Increased LSE in thought and means was the core of the second theme that emerged. The artifact and field note analyses revealed the phrase confidence to lead over 35 times, and the same phrase, along with the ability to lead, was stated 15 times across interview transcripts. When candidates start the doctoral program, some are already in leadership positions, some transitions to leadership positions while in the program, and others either move into positions after graduation. The changes that candidates went through to become leaders during the program were reflected in comments from other faculty members. In particular, faculty observed candidates develop LSE by applying scholarly inquiry through authentic problems of practice as noted in leadership actions and reflective dialogue. Similar to what Thompson et al. (2015) discuss, the faculty serve as mentors while candidates practice inquiry in their coursework. In the change leadership course, candidates examine cases of leadership addressing problems of practice with instructor guidance. Candidates reflected on their learning as leaders (Thanaraj, 2016) and confidence in collaboratively analyzing systems within organizations (Jenkins, 2020; Sudirman \& Gemilang, 2020), which, in turn, increased their perceptions of seeing themselves as capable leaders through challenging situations as the LSE framework (Hannah et al., 2013) theorizes.

The participants described this LSE as becoming more self-confident and knowing what to do in a leadership situation; thus, increasing both thought and means for enacting leadership moves. For example, one participant stated, "I feel like now 
I've learned new ways of thinking as a leader, and I've learned this through the doctorate program. I feel like after I graduated I now feel more confident in my ability to lead." After explaining how they gleaned new resources and ways of thinking about situations encountered as a leader, another participant added, "I'm more than ever, confident." After reflecting on their learning from program faculty, a different participant also noted that "I am much more confident in my ability to lead change and manage change, and much more confident in assessing problems of practice and looking for collaborative solutions. It's just been fabulous - hard of course, but fabulous."

After reflecting on the newly learned skills, another participant shared that their confidence (LSE in thought and means) grew incrementally throughout the phases of the CPED program, which in turn, highlights an impact on LSE in selfmotivation and action to lead:

"There's a tremendous level of confidence about leading that I heard talked about before I started the program and then began to actually experience it towards the latter end of the program especially once it was ending. That was really unexpected. I used to consider myself in the lowest way confident. Now, after learning new skills and ways of tackling issues over the program and the network we established...and the resources, I am confident to lead and I know I have what I need to make things happen. Now I am a change leader doing the work, not watching others and hoping to be one."

A different participant reflected on how their newfound confidence in leading increased their ability to lead. This alluded to the growth of LSE in thought, means, and action:

"[I developed] a broader perspective of education... and in doing that it gave me confidence to know that things I've done in the past or have not done or heard about I can now do... it's just that the process of educational leadership itself is a system and is one that is as critical as I thought, and it is as urgent as I believed it was. And now I have what it takes to be a leader with the tools and processes I have learned through the program."

Some participants did not directly use the term confidence but described it through a reflection on new awareness, which highlighted, once again, the impact of the program on LSE in thought and means. For example, one participant shared:

"[The program] made me more aware of myself. I have become more aware of my weaknesses and my strengths and I tried to figure out how to use them in my everyday role as a leader in my organization. I believe I am a better leader overall because of being able to do this."

Another participant highlighted:

I think my ability to lead has grown. It's fascinating. It isn't tangible. You have to think about how to do the leading before you actually do it... and you have to know you have all the resources you need -- the people, the ideas, the plan, the theory of action -- before you say, 'Ok, let's make change." 


\subsubsection{Theme three: Inquiry is a learned skill developed through a focus on problems of practice}

Overall, participants explained how, as leaders, they focus on problems of practice in the field. The participants all noted, in various ways, that thinking about and working on problems of practice continued beyond the program. One participant, from the context of their current leadership position, shared their views of the job as revolving around facilitating teams to find solutions for problems of practice:

Well, the very nature of our work is a problem of practice because of course, what we're doing is taking a look at the statistics that are gathered on the problem that we're involved in so that we can then make plans to improve the program... well, really, first to find aligned scholarly research to apply to the issue or the plan and then we jump in and...keep progress notes... so we can track the progress of each plan and then from that make modifications for the overall program that we have.

A different participant named problems of practice and the cycle of improvement using different terms, but highlighted similar overtones of scholarly inquiry to address issues as a leader because of the CPED program:

"Because of the doctoral program I am now more adept at leading teams and addressing various situations, or problems of practice. Whether or not I call them that is kind of inconsequential. I do just see things differently, and I do handle them differently and process them differently, with research and systems for thinking to back up what we are doing. Not just trying something new just because it is new, but developing a plan for improvement based on what has already been reported to actually work in a given context. That is all different for me as a leader now."

Further, participants discussed viewing problems of practice indicated another way these participants had embodied working on complex situations beyond the program (e.g., Hamann \& Trainin, 2018). For example, one of these participants described their way of viewing problems using a metaphor:

"I feel that it's more of a definition or refining of who I am as a leader. I had some qualities coming in. It's given me an opportunity to view things and expand on the skills I had. To view things slightly differently, to expand on who I am. If you think of a person with two eyes that puts on a pair of glasses, there are four ways to vision, theoretically. I think of that kind of development within myself. A lot of clarity, a lot of paying attention to the smaller details, versus just the bigger picture of leadership. The details help lead you to the right research for the specific need and then, in turn, that gives you lenses for a plan in the bigger picture. Zooming in and zooming out all at once with the research and planning process helping to focus the view..."

These applied analysis skills are a goal of the CPED framework (2019b), noted in one guiding principle of CPED influenced programs: To provide field-based opportunities to analyze problems of practice and use multiple frames to develop meaningful solutions. If candidates are working on analyzing authentic problems of practice through course content, they become more likely to understand how to address difficult problems that occur within the diverse organizations they serve. In this way, the terms analysis or analyzing were mentioned six times in 
conjunction with problem-solving. For example, one participant specifically noted, "The problem of practice really exists within the analysis and strategic problem-solving." Another detailed how they led a team of colleagues through data analysis to begin problem-solving after developing and conducting an organizational climate survey:

"We got together to analyze why we thought that we got the negative responses, what exactly our practices were, and how we could improve them...The skills that I learned in analysis and in using data to make generalizations about an issue have been invaluable to me and I see myself as a problem solver. But a scholarly one now. I mean I would have never thought to develop or had the skills to develop and execute, a reliable survey to help make leadership decisions. Not before this program."

Likewise, a separate participant discussed skills in analysis as part of their work as a problem-solving type of educational leader:

"You realize the critical nature of analyzing and involving all the stakeholders in your initial assessment of what the root causes actually are and whether or not your plan will ultimately have an impact on the perceived problem of practice."

So in terms of helping me with the problem of practice I would say that the continuous process really helped me in that area...it really is something I rely on in my current job."

Furthermore, participant responses regarding their work with problems alluded they were inquiring deeply into contexts, applying research-based methods, well and drawing upon literature to support both problem analysis and next steps for addressing the problem in the short and long terms - all components of the cycle of continuous improvement taught and used across the nine core courses of this CPED program. For example, a participant directly described the continuous improvement cycle:

"Our team that I work on, my current role, is made up of essentially five people: one team leader and four team members so to speak. Our process in designing this team and our charge to support school districts and maintaining...the systems leadership through the continuous improvement model."

\section{Evaluation Summary by Research Question}

How does a CPED doctoral program support candidates in cultivating their leader selfefficacy as problem-solving scholar-practitioners? In terms of cultivating LSE, the case study evaluation findings demonstrate that the CPED program supports candidates in specific ways. Response trends highlighted the ways the program, with an emphasis on scholarly inquiry (e.g., Cunningham et al., 2019; Rogers et al., 2016) of field-based problems of practice (e.g., Hamann \& Trainin, 2018; Lenihan et al., 2015) as was transformational for graduates as educational leaders. As viewed through LSE (Hannah et al., 2013), the findings illuminated how leaders are self-motivated to take action when they perceive they have critical thinking processes. As shown through Theme One, the participants noted they had changed, in thought by having new ways to consider how to address problems of practice, and in motivation by finding a previously untapped voice that shifted 
the perception of being able to lead so they could enact change. Theme Two emphasized how graduate LSE was positively impacted by the program, noting an increase in confidence and self-awareness. Participants described this impact in ways that illustrated how the program aided in strengthening their selfperceptions as leaders because they were afforded opportunities to develop critical thinking strategies and resources in which to draw on as leaders in the field. It is clear that graduates of a CPED program, with a focus on cultivating problem-solving scholar-practitioners, do benefit from an increase in overall LSE by tapping into the sub-constructs through field-based coursework on authentic problems of practice (Cunningham et al., 2019; Lenihan et al., 2015) by committed faculty mentors (Thompson et. al, 2015).

To what extent do these CPED program graduates, as scholar-practitioners, continue to solve problems of practice in the field? These CPED graduates seemed to focus on problems of practice to a great extent in their current work environments. As educational leaders in the field, participants perceived their work to revolve around solving problems of practice noting how this way of thinking was central to being a leader. This aligns with Morison (2018) findings of where leaders will continue to access the status quo unless they are empowered to use deep collaborative inquiry to solve problems for continuous improvement, which participants alluded to in their responses. Also, by fostering specific leadership practices for critical thinking throughout the CPED program, the new practices became part of their leadership repertoire after graduation, which aligns with the findings of Cunningham et al. (2019) and Jenkins (2020). Emphasizing the work of Chiptin (2014) and Hamann \& Trainin (2018), these CPED graduates also highlighted how they addressed problems of practice in the organization beyond teaching and learning to enact change. The CPED (2019) goals for a redesigned program for true widespread impactful change in the field were demonstrated with this set of graduate participants.

\section{Conclusion}

Graduates from this CPED program believe they can adapt as leaders, a critical program outcome because of their increased LSE in thought, means, selfmotivation, and practice in action. Constant change is a real factor within the increasingly complex PreK-12 and higher education settings. The skill sets required within redesigned $C P E D$ doctoral programs support critical inquiry processes that help graduates recognize and adapt to leadership challenges in the field. By incorporating scholarly practices of collaborative critical inquiry into the problem landscape and self-reflection on the processes, practitioners can more efficaciously enact meaningful change.. While the program Context and Input evaluations highlighted aspects of social justice, limited to no evidence was found in the Process and Product evaluations, illuminating an area of growth for this doctoral program to meet CPED goals and truly prepare leaders for the diverse context of the region they will serve.

Thus, based on the evaluation findings, to cultivate LSE and support the continued use of problem-solving after graduation, programs should consider:

- The use of critical collaborative scholarly inquiry into authentic problems of practice. 
- The application of field-based experiences in local contexts where future leaders will serve.

- The incorporation of critical thinking and reflective practice of ongoing leadership development through these experiences.

- The intentional integration of social justice as a foundation for change leaders.

These are essential considerations for current educational leadership EdD programs when evaluating how they prepare graduates who will impact education beyond coursework. Further research on the long-term impact of other CPED guiding principles, specifically to include areas of problems of practice on access, ethics, and social justice, are critical to understanding the broader social impact graduates have in the field upon program completion.

\section{References}

Arrieta, G. S., \& Ancho, I. V. (2020). Ready or Not: The Experiences of Novice Academic Heads in School Leadership. International Journal of Learning, Teaching and Educational Research, 19(5), 78-98. doi:10.26803/ijlter.19.5.5

Auerbach, S. (2011). "It's not just going to collect dust on a shelf:" Faculty Perceptions of the Applied Dissertation in the New California State University (CSU) EdD Programs Leadership Education from within a Feminist Ethos. Journal of Research on Leadership Education, 6(3), 59-82. doi:10.1177/194277511100600301

Bandura, A. (1977a). Self-efficacy: The exercise of control. New York: W. H.

Bandura, A. (1977b). Self-efficacy: Toward a unifying theory of behavioral change. Psychological Review, 84, 191-215.

Buss, R. R. (2018). How CPED guiding principles and design concepts influenced the development and implementation of an EdD program. Impacting Education: Journal on Transforming Professional Practice, 3(2), 40-47. doi:10.5195/ie.2018.57

Chitpin, S. (2014). Principals and the professional learning community: Learning to mobilize knowledge. International Journal of Educational Management, 28(2), 215229. doi:10.1108/IJEM-04-2013-0044

Chowdhury, I. A. (2015). Issue of quality in a qualitative research: An overview. Innovative Issues and Approaches in Social Sciences, 8(1), 142-162. doi:10.12959/issn.18550541.iiass-2015-no1-art09

CPED. (2019a). Carnegie project on the education doctorate. Retrieved Nov. 25, 2020 from https:/ / www.cpedinitiative.org/

CPED. (2019b). The framework: Guiding principles on the program design. Retrieved Nov. 24, 2020 from https:/ / www.cpedinitiative.org/the-framework

Cresswell, J. A., \& Poth, C.N. (2018). Qualitative inquiry and research design: Choosing among five approaches, fourth edition. Thousand Oaks, CA: Sage Publications.

Cunningham, K. M. W., VanGronigen, B. A., Tucker, P. D., \& Young, M. D. (2019). Using powerful learning experiences to prepare school leaders. Journal of Research on Leadership Education, 14(1), 74-97. doi:10.1177/1942775118819672

Denzin, N. K. (2017). Critical qualitative inquiry. Qualitative Inquiry, 23(1) 8-16. doi:10.1177/1077800416681864

Fairholm, M. R. (2014). Trans-leadership linking influential theory and contemporary research. In R. S., Morse, T. F., Buss \& C. M, Kinghorn, (eds.), Transforming public leadership for the 21 st century, 105-124. New York: Routledge. doi:10.4324/9781315698588

Gibbs, G. (1988). Learning by doing: A guide to teaching and leading reform. Oxford, UK: Oxford Centre for Staff and Learning Development, Oxford Brookes Institute. 
Gibney, J. (2011). Knowledge in a "shared and interdependent world": Implications for a progressive leadership of cities and regions. European Planning Studies, 19(4), 613627. doi:10.1080/09654313.2011.548474

Hamann, E. T., \& Trainin, G. (2018). Problems of practice as stance. Impacting Education: Journal on Transforming Educational Practice, 3(2), 48-50. Retrieved Nov 28, 2020 from https://digitalcommons.unl.edu/teachlearnfacpub/346/

Hannah, S. T., Avolio, B. J., Luthans, F., \& Harms, P. D. (2008). Leadership efficacy: Review and future directions. The Leadership Quarterly, 19(6), 669-692. doi:10.1016/j.leaqua.2008.09.007

Hannah, S. T., Avolio, B. J., Walumbwa, F. O., \& Chan, A. (2012). Leader self and means efficacy: A multi-component approach. Organizational Behavior and Human Decision Processes, 118(2), 143-161. doi:10.1016/j.obhdp.2012.03.007

Hannah, S. T., Avolio, B. J., Walumbwa, F. O., \& Chan, A. (2013). Leader self and means efficacy measure. PsycTESTS Dataset. doi:10.1037/t24459-000

Hannah, S. T., Woolfolk, R. L., \& Lord, R. G. (2009). Leader self-structure: a framework for positive leadership. Journal of Organizational Behavior: The International Journal of Industrial, Occupational and Organizational Psychology and Behavior, 30(2), 269-290. doi:10.1002/job.586

Hovannesian, A. (2013). CPED: Reshaping perceptions of the scholarly practitioner. Planning and Changing, 44(3/4), 308-316. Retrieved Nov 28, 2020 from https:/ / eric.ed.gov/?id=EJ1145947

Jenkins, D. (2020). What the best leadership educators do: A sequential explanatory mixed methods study of instructional and assessment strategy use in leadership education. Journal of Leadership Education, 19(4). doi:10.12806/v19/i4/r4

Kennedy, B. L., Bondy, E., Dana, N. F., Vescio, V., \& Ma, V. W. (2019). The development and enactment of practitioner scholarship among graduates from one online Ed.D. programme. Journal of Further and Higher Education, 44(5), 653-669. doi:10.1080/0309877x.2019.1576858

Lenihan, P., Welter, C., Brandt-Rauf, P., Neuberger, B., Pinsker, E., Petros, M., \&Risely, K. (2015). The University of Illinois at a Chicago school of public health doctor of public health program: An innovative approach to doctoral-level practice leadership development. American Journal of Public Health, 105(1), S55-S57. doi:10.2105/ajph.2014.302331

Levine, A. (2005). Educating school leaders. Princeton, NJ: The Woodrow Wilson National Fellowship Foundation.

Morrison, A. R. (2018). Beyond the status quo - setting the agenda for effective change. Educational Management Administration \& Leadership, 46(3), 511-529. doi:10.1177/1741143216682500

Murphy, J. \& Vriesenga, M. (2007). Research on school leadership preparation in the United States: An analysis. School Leadership and Management, 26(2), 183-195. doi:10.1080/13634230600589758

Peterson, D. S. (2017). Preparing scholarly practitioners: Redesigning the EdD to reflect CPED principles. Impacting Education: Journal on Transforming Professional Practice, 2(1). doi:10.5195/ie.2017.30

Peterson, D. S., Perry, J. A., Dostilio, L. D., \& Zambo, D. (2016). Community engaged faculty: A must for preparing impactful EdD graduates. Metropolitan Universities Journal, 27(2): 59-73. doi:10.18060/21127

Peurach, D. J. (2016). Innovating at the nexus of impact and improvement: Leading educational improvement networks. Educational Researcher, 45(7), 421-429. doi:10.3102/0013189X16670898 
Ramsey, A. (2019, January 25). The poverty line in Fresno. Fox 26 News. Retrieved Nov 28, 2020 from https:// kmph.com/news/local/the-poverty-line-in-fresno

Rettke, H., Pretto, M., Spichiger, E., Frei, I. A., \& Spirig, R. (2018). Using reflexive thinking to establish rigor in qualitative research. Nursing Research, 67(6), 490-497. doi:10.1097/nnr.00000000000000307

Rogers, R., Schaenen, I., Schott, C., O'Brien, K., Trigos-Carrillo, L., Starkey, K., \& Chasteen, C. C. (2016). Critical discourse analysis in education: A review of the literature, 2004-2012. Review of Educational Research, 86(4), 1192-1226. doi:10.3102/0034654316628993

Sierra Health Foundation. (2016). California's San Joaquin Valley: A region and its children under stress. UC Davis Center for Regional Change: Hartzog, C., Abrams, C., Erbstein, N., London, J. K. \& Watterson, S. Retrieved Nov 28, 2020 from https://www.sierrahealth.org/assets/pubs/A_Region_and_Its_Children_Unde r_Stress-Web.pdf

Stufflebeam, D. L., \& Zhang, G. (2017). The CIPP evaluation model: How to evaluate for improvement and accountability. New York, NY: Guilford Publications.

Sudirman, A., \& Gemilang, A. V. (2020). Promoting work-based learning as a praxis of educational leadership in higher education. International Journal of Learning, Teaching and Educational Research, 19(3), 149-173. doi:10.26803/ijlter.19.3.9

Thanaraj, A. (2016). Improving leadership practice through the power of reflection: an epistemological study. International Journal of Learning, Teaching and Educational Research, 15(9), 28-43. Retrieved Nov 28, 2020 from http://ijlter.org/index.php/ijlter/article/view/757/pdf

Thompson, J., Hagenah, S., Lowhwasser, K., \& Laxton, K. (2015). Problems without ceilings: How mentors and novices frame and work on problems-of-practice. Journal of Teacher Education, 66(4), 363-381. doi:10.1177/0022487115592462

University of Cumbria. (2020). Gibb's Reflective Cycle. Retrieved Nov 28, 2020 from https://my.cumbria.ac.uk/media/MyCumbria/Documents/ReflectiveCycleGi bbs.pdf

Vasudeva, A. (2017). Adapted from the 2017 CPED convening presentation: Reflections and new directions on CPED's $10^{\text {th }}$ anniversary. Impacting Education: Journal on Transforming Professional Practice, 2(1), 1-5. doi:10.5195/ie.2017.47

Welch, O. M. (2013). Interrogating our practice: Enacting a "yes and" CPED agenda at Duquesne university. Planning and Changing, 44(3/4), 149. Retrieved Nov 28, 2020 from https:/ / eric.ed.gov/?id=EJ1145892

Zambo, D. (2013). Elbow learning about change, leadership and research in an CPEDinfluenced program. Planning and Changing, 44(3/4), 237. Retrieved Nov 28, 2020 from https:/ / eric.ed.gov/?id=EJ1145923

Zambo, D., Buss, R. R., \& Zambo, R. (2015). Uncovering the identities of candidates and graduates in a CPED-influenced EdD program. Studies in Higher Education, 40(2), 233-252. doi:10.1080/03075079.2013.823932 


\section{Appendix 1}

\section{Interview Questions}

\section{Rapport Building}

1. How are you feeling after finally graduating from the program?

2. Tell me about your current role in education?

\section{Problems of Practice in the Program}

3. Tell me about the problem of practice you focused on in your dissertation?

4. Did the program help you think about your problems of practice as you moved towards and through the dissertation phase?

5. In what ways did the program help you, or not helped you, define and address your problem of practice?

\section{Problems of Practice Beyond the Program in Current Leadership Role}

6. What leadership work are you involved in now?

7. How do you address issues to enact change in your current context as problems of practice?

\section{Program Evaluation}

8. What did the program offer that has helped you define your current work through the lense of a problem of practice?

9. What can be strengthened in the program to help you continue?

10. How do you feel you grew your abilities to lead because of the program?

11. How do you feel about your ability in approaching problems of practice in your current role through scholarly inquiry rather than merely solving problems or putting out fires?

\section{Additional Information}

12. Do you have anything else to share about your growth as a leader because of the program that I have not yet asked you about? 